\title{
Chronic Fatigue Syndrome: The Need for an Integrative Approach
}

The syndromal presentation of chronic fatigue, feverishness, diffuse pains and other constitutional complaints, often precipitate $J$ by an acute infectious illness and aggravated by physical and emotional stressors, has a lengthy history. It has been described in the medical literature since the early 1700's. Sir Richard Manningham wrote, in 1750, of the 'febricula' or 'little fever' which pre sented with a variety of constitutional complaints, but few objective clinical findings (Manninghan 1750). One of the more lasting appellations for this cluster of symptoms, 'neurasthenia,' was introduced by George Beard in the late 19th century, and is still used today in the 9th Revision of the World Health Organization's International Classification of Diseases (Beard 1869). Beard maintained that the etiology of this syndrome resided in subtle and undetectable alterations in neurochemistry, but the pathophysiology remains unknown more than a century later. Recent investigators have emphasized its heterogeneity, the multiple terms used to describe the syndrome, and its possible connections to other proposed entities such as fibromyalgia (Straus 1988a; Swartz 1988). The situation remains confusing.

To facilitate identification of objective characteristics and improve comparability of research studies, the Centers for Disease Control recently proposed a working case definition, renaming the illness "chronic fatigue syndrome" (Holmes et al 1988). Essentiaily, patients meeting criteria for the syndrome must have persistent or relapsing, debilitating fatigue for at least six months in the absence of any apparent medical diagnosis which would explain the clinical presentation. The CDC symptom criteria for this syndrome are presented in Table 1.

Two principal theories have dominated pathophysiologic concepts of this syndrome. One view has focused on the behavioral antecedents of the illness and maintains that this disorder represents the behavioral aftermath of an acute infectious event in psychologically susceptible individuals. In 1941, Paul Wood wrote, “. . . patients should be informed of the nature of their illness and be treated as psychoneurotics; their distaste for this label may prove quite helpful. . . The patient must be induced to believe that he is suffering from the effects of emotional disturbance and not from any disease or alteration of visceral function ..." (Wood 1941). An alternate view has emphasized the importance of the infectious onset, with the protean constitutional symptoms emerging secondary to persistent immune activation and/or other lasting pathophysiclogic changes caused by the initial infectious event. Inadequate attention has been given to how these two views might interface.

A number of early studies served to bolster the 'behavioral' viewpoint noted above. In 1951, Spink studied 65 patients with documented acute brucella infection, and noted that approximately 20 per cent of these patients proceeded to have proionged symptoms without any objective evidence of continued active disease (Spink 195i). He observed a high degree of psychological morbidity in this subgroup of patients, and speculated that, “. . . individuals with functional complaints or personality difficulties may have an ex- 
Table 1. Centers for Disease Control (CDC) Case Criteria for Chronic Fatigue Syndrome

Major Criteria: (Patient must fulfill major criteria 1 and 2)

1) New onset of persistent or relapsing, debilitating fatigue or easy fatigability that does not resolve with bedrest and is severe enough to impair average daily activity below $50 \%$ of premorbid activity level, lasting for a period of at least 6 months.

2) Exclusion of other clinical conditions or medication effects by appropriate history, physical examination or laboratory tests.

Minor Critera: (Patient must show 6 or more of the symptom criteria and 2 or more of the physical criteria; or $\mathbf{8}$ or more of the symptom criteria)

Symptom criteria (must have begun at or after onset of the fatigue and must be persistent or recurring):

1) Mild fever or chills

2) Sore throat

3) Painful anterior or posterior cervical or axillary lymph nodes

4) Generalized muscle weakness

5) Myalgias

6) Prolonged post-exertional fatigue

7! Headaches

8) Migratory arthralgia

9) Neuropsychologic complaints (incl., photophobia, transient scotomata, forgetfulness, irritability, confusion, depression, poor concentration)

10) Sleep disturbance

11) Main symptom complex having an abrupt onset

Physical criteria: (must be documented on at least two occasions, at least one month apart)

1) Low grade fever (oral $\mathrm{T} 3 ? .6-38.6^{\circ} \mathrm{C}$ or rectal $\mathrm{T} 37.8-38.8^{\circ} \mathrm{C}$ )

2) Nonexudative pharyngitis

3) Palpable anterior or posterior cervical or axillary lyn:pl nodes

aggeration of these manifestations following acute brucellosis. . . Using more formalized psychological and medical assessments, Imboden and Cluff, at Johns Hopkins University, arrived at a similar -onclusion (Imboden et al 1959). They summarized that chronic brucellosis, “. . . consists mostly of an emotional disorder. . . ." Reasoning that the factors involved in the delay of symptomatic recovery from acute brucellosis might be applicable to other acute infections, Imboden and Cluff designed a prospective psychological evaluation of 600 individuals prior to the onset of the expected nationwide epidemic ol Asian influenza in 1957 (Imboden 1961). Twenty-six individuals developed the influenza syndrome; 12 had symptoms that persisted beyond three weeks. Their prospective evaluation confirmed that patients in the persistently ill group showed uniformly higher levels of pre-illness psychological distress. Recently published studies using structured psychiatric interview techniques have also suggested that the prevalence of psychiatric illness was higher in patients with chronic fatigue syndrome than in the general population, and often preceded the onset of the fatigue syndrome (Taerk et al 1987; Manu et al 1988; Manu et al 1989; Kruesi et al 1989; Gold et al 1990). Only one study reported the prevalence of psychiatric illness to be comparable to that of the general population, and to follow, rather than precede the development of the chronic fatigue (Hickie et al 1990). However, lacking reliable biological measures to idenitify this syndrome, and given that most established psychiatric diagnostic systems include fatigue as a symptom of psychiatric disorder, the use of phenomenologic criteria alone introduces an unavoidable circularity of reasoning when trying to establish a definitive distinction between chronic fatigue and a psychiatric illness. 
Evidence supporting an infectious or persistent immune dysregulation hypothesis for the pathophysiology of chronic fatigue has largely emerged from a series of reports which began appearing between 982 and 1985 . These studies reported a spectrum of subile abnormalities in cell-mediated and humoral immunity in these patients, along with atypical profiles of antibody responses to the Epstein-Barr virus and other viral antigens (Tobi et al 1982; Jones et al 1985; Straus et al 1985). These immunologic disturbances, coupled with the clinical observation that many of these patients developed the syndrome following an episode of acute infectious mononucleosis, led to the specific hypothesis that the illness was a manifestation of chronic Epstein-Barr virus infection. However, several subsequent observations challenge this idea and suggest that, while immune activation may be present in these patients, persistent Epstein-Barr virus infection is almost certainly not a tenable explanation for most cases of the syndrome. First, the magnitude or pattern of the antibody titers bears no relationship to the severity of the clinical presentation. Furthermore, controlled studies of seroepidemiology showed that enhanced activity of the Epstein-Barr virus may persist for as long as 30-104 months after the acute infection in otherwise asymptomatic indiviciuals (Horwitz et al 1985; Holmes et al 1987; Buchwald et al 1987). Finally, a controlled trial of intravenous and oral acyclovir was without effect in patients with chronic fatigue syndrome (Straus et al 1988b). Nevertheless, a role for persistent pathophysiologic changes following an acute viral infection, has not been excluded as a possible pathogenesis of chronic fatigue syndrome. Indeed, Oldstone and colleagues, have provided evidence in animals demonstrating that viral infections may lead to longlasting pathologic changes in differentiated cellular functions, long after the infection itself has resolved (Oldstone et al 1982). This process may result in substantial disturbances in organismic humeostasis, without damaging the morphologic appearance of the infected cells.

Despite the prominence of central nervous system symptoms in these patients, remarkably few studies of this syndrome have involved investigators skilled in psychiatry. The lack of such involvement has consistently impaired an integrative undirstanding of this syndrome, limited the development of new pathophysiologic models, perpetuated the stigma associated with behavioral symptoms, and fostered methodologic problems in research. At the present time, a scientific bias in research in this area persists in the form of a search for a specific, infection-produced disturbance in immune function. This is the case despite the fact that there exists little evidence to suggest that the observed mild immune abnormalities are of any functional significance. Psychiatrically ill comparison groups have been virtually absent, with one important exception (Wessely, Powell 1989). In their study, Wessely and Powell conclude that the description of fatigue in patients with "postviral" fatigue syndrome more closely resembled a comparison group of affectively ill patients than a group of patients with primary neuromuscular disorders. However, they emphasize that depression alone cannot be the sole explanation for the similarity in phenomenologic presentation. Nearly one third of all patients with "postviral" fatigue had no diagnosable psychiatric disorder. In their words, "[chronic fatigue syndrome] is a heterogenous condition, depressive illness is a sufficient, but not necessary, explanation. ..."

An interdisciplinary approach to studies in this area is advocated; psychiatry should be a primary component of such an approach. It is ironic that most non-psychiatric researchers in this field have long acknowledged the need for such involvement. For instance, a formal structured psychiatric interview is now considered to be an essential component of a credible research workup for chronic fatigue syndrome. These issues 
were discussed in detail at a recent workshop on the Definition and Medical Outcome Assessment of Chronic Fatigue Syndrome in Research, sponsored jointly by the National Institute of Mental Health and the National Institute for Allergy and Infectious Diseases. This commendable joint effort represented the first formal involvement of the NIMH in this area.

To begin exploring potential biological underpinnings of the clinical common ground between chronic fatigue syndrome and primary psychiatric illness, we recently advanced data suggesting that the phenomenologic overlap may reflect the occurrence of a shared, final common biological pathway that may be precipitated by a variety of infectious or non-infectious pathophysiologic antecedents (Demitrack et al 1991). Several lines of evidence implicate disturbances in the hypothalamic-pituitary-adrenal axis as this shared final pathway. First, a review of the clinical presentation of chronic fatigue syndrome shows considerable overlap with that seen in patients with giucocoricoid deficiency (Baxter et al 1981). Indeed, one of the principal symptoms of glucocorticoid deficiency is debilitating fatigue. An abrupt onset precipitated by a stressor, feverishness, arthralgias, myalgias, adenopathy, postexertional fatigue, exacerbation of allergic responses, and disturbances in mood and sleep are also characteristic of glucocorticoid insufficiency. Notably, these symptoms are often seen in the relatively rare syndrome of partial or subclinical adrenal insufficiency, which may only be detectable by ACTH stimulation or other endocrine testing in patients who fail to show the symptoms of classical Addison's disease, such as hypotension and abnormal fluid and electrolyte balance. Sirice glucocorticoids represent the most potent endogenous immunosuppressive agents, we further suggest that many of the observed immunologic disturbances in patients with chronic fatigue syndrome (e.g., exacerbation of allergic responses, and the profile of enhanced antibody titers to a variety of viral antigens) could also reflect a mild glucocorticoid deficiency. In this regard, it has recently been shown in animals that a defect in the responsiveness of the hypothalamic-pituitary-adrenal axis to immune mediators confers a risk for the development of inflammatory disease (Sternberg et al 1989a; Sternberg et al $1989 \mathrm{~b})$.

A second line of evidence implicating disturbances in the functional integrity of the hypothalamic-pituitary-adrenal axis focuses upon corticotropin-releasing hormone. Other clinical populations with similar behavioral features characterized by profound lethargy, fatigue and depressed mood (often .eferred to as 'atypical' depressive syndromes), may show evidence of hypofunctioning of hypothalamic corticotropin-releasing hormone neurons. These illnesses include Cushing's disease (Kling et al 1991; Tomori et al 1983), hypothyroidism (Kamilaris et al 1987), and the depressed phase of seasonal affective disorder (Joseph-Vanderpool et al 1991). These findings are of interest because corticotropin-releasing hormone serves not only as the principal stimulus to the pituitaryadrenal axis, and hence could be involved in cases of subtle adrenal insufficiency, but also because it is a behaviorally-active reurohormone whose central administration to animals and non-human primates induces signs of physiological and behavioral arousal, including activation of the sympatinetic nervous system (Brown et al 1982), hyperresponsiveness to sensory stimuli (Swerdlow et al 1986), and increased locomotion (Sutton et al 1982). Hence, a functional deficit of hypothalamic corticotropin-releasing b ormone could contribute to the profound lethargy and fatigue that are inherent characteristics of both 'atypical' depressive syndromes and chronic fatigue syndrome, either through direct effects upon the central nervous system or indirectly by causing glucocorticoid deficiency. In summary, we have hypothesized that a variety of infectious or non-infectious patho- 
physiologic antecedents may lead to a specific neuroendocrine deficit, namely, a reduction in adrenal glucocorticicid secretion mediated by an impairment in the central nervous system regulation of the axis. This pattern of secondary adrenal insufficiency, in tum, may be a consequence of as well as a causative factor in the development of many of the behavioral and biochemical abnormalities that have been described in patients with chronic fatigue syndrome. Similarly, other clinical states, with widely differing pathophysiologies, may result in a fatigue-like syndrome due to a functional deficit in hypothalamic corticotropin-releasing hormone.

The validity of this model remains to be determined. Of greatest importance, available data indicate that as investigators evaluate this model, or any other, an integrated, interdisciplinary perspective is crucial. Characteristics essential to such an approach include thorough psychiatric assessments using standardized instruments with demonstrated reliability and validity, comparative analyses employing clearly defined psychiatric populations, and neurobiological models which address the interaction of brain and behavior in the clinical expression of this illness.

Mark A. Demitrack John F. Greden

\section{Department of Psychiatry}

University of Michigan Medical Center

1500 East Medical Center Drive

Ann Arbor, Michigan 48109-0116

\section{References}

Baxter, JD, Tyrell, JB (1981): The Adrenal Cortex. Ir. Felig P, Baxter JD, Broadus AE, Frohman LA (eds), Endocrinology and Metabolism. New York: McGraw-Hill, pp 385-510.

Beard G (1869): Neurasthenia, or nervous exhaustion. Boston Med Surg J III(13):217-221.

Brown MR, Fisher LA, Spiess J, Rivier C, Rivier J, Vale W (1982): Corticotropin-releasing factor: Actions on the sympathetic nervous system and metabolism. Endocrinology 111:928-931.

Buchwald D, Sullivan JL, Komaroff AL (1987): Frequency of 'chronic active Epstein-Barr virus infection' in a General Medical Practice. JAMA 257:2303-2307.

Demitrack MA, Dale JK, Straus SF, et al (1991): Impaired activation of the hypothalamic-pituitaryadrenal axis in patients with chronic fatigue syndrome. J Clin Endocrinol Metab (in press).

Gold D, Bowden R, Sixbey J, et al (1990): Chronic fatigue: A prospective clinical and virologic study. JAMA 264:48-53.

Hickie I, Lloyd A, Wakefield D, Parker G (1990): The psychiatric status of patients with chronic fatigue. Br J Psychiatry 156:534-540.

Holmes GP, Kaplan JE, Gantz NM, et al (1988): Chronic fatigue syndrome: A working case definition. Ann Intern Med 108:387-389.

Holmes GP, Kaplan JE, Stewart JA, Hunt B, Pinsky PF, Schonberger LB (1987): A cluster of patients with a chronic mononucleosis-like syndrome: Is Epstein-Barr virus the cause? JAMA 257:2297-2302.

Horwitz CA, Henle W, Henle G, Rudnick H, Latts E (1985): Long-term serological follow-up of patients for Epstein-Barr virus after recovery from infectious mononucleosis. J Infect Dis 151:11501153.

Imboden JB, Canter A, Cluff LE, Trever RW (1959): Brucellosis III. Psychological aspects of delayed convalescence. Arch Intern Med 103:78-86.

Imboden JB, Canter A, Cluff LE (1961): Convalescence from influenza. Arch Intern Med 108:393399. 
Jones JF, Ray G, Minnich LL, Hicks MJ, Kibler R, Lucas, DO (1985): Evidence for active EpsteinBarr virus infection in patients with persistent, unexplained illnesses: Elevated anti-early antigen antibodies. Ann Intern Med 102:1-7.

Joseph-Vanderpool JR, Rosenthal NE, Chrousos GP, et al (1991): Abnormal pituitary-adrenal responses to $O C R H$ in patients with seasonal affective disorder: Clinical and pathophysiological implications. J Clin Endocrinol Metab 72:1382-1387.

Kamilaris TC, DeBold CR, Pavlou SN, Island DP, Hoursandis A, Orth DN (1987): Effect of altered thyroid hormone levels on hypothalamic-pituitary-adrenal function. J Clin Endocrinol Metab 65:994-999.

Kling MA, Roy A, Doran AR, et al (1991): Cerebrospinal fluid immunoreactive CRH and ACTH secretion in Cushing's disease and major depression: Potential clinical implications. J Clin Endocrinol Metab 72:260-271.

Kruesi MJP, Dale JK, Straus SE (1989): Psychiatric diagnoses in patients with the chronic fatigue syndrome. I Clin Psychiatry 50:53-56.

Manningham R (1750): The Symptoms, Nature, Causes, and Cure of the Febricula, or Little Fever. London: J Robinson.

Manu P, Lane TJ, Matthews DA (1988): The frequency of the chronic fatigue syndrome in patients with symptoms of persistent fatigue. Ann Intern Med 109:554-556.

Manu P, Matthews DA, Lane TJ, et al (1989): Depression among patients with a chief complaint of chronic fatigue. $J$ Affective Disord 17:165-i72.

Oldstone MBA, Sinha YN, Blount P, et al (1982): Virus-induced alterations in homeostasis: alterations in differentiaied functions of infected cells in vivo. Scienr: 218:112j-1127.

Spink WW (1951): What is Chronic Brucellosis? Ann Intern Med 35:258-374.

Sternberg EM, Hill J, Chrousos GP, et al (1989a): Inflammatory mediator-induced hypothalamicpituitary-adrenal activation is defective in streptococcal cell wall arthritis-susceptible rats. Proc Natl Acad Sci USA 86:2374-2378.

Sternberg EM, Young WS III, Bernardini R, et al (1989b): A central nervous system defect in biosynthesis of corticotropin-releasing hormone is associated with susceptibility to streptococcal cell wall-induced arthritis in Lewis rats. Proc Natl Acad Sci USA 86:4771-4775.

Straus SE (1988a): The chronic mononucleosis syndrome. J Infect Dis 157:405-412.

Straus SE, Dale JK, Tobi M, et al (1988b): Acyclovir treatment of the chronic fatigue syndrome: Lack of efficacy in a placebo-controlled trial. $N$ Engl $J$ Med 319:1692-1698.

Straus SE, Tosato G, Armstrong G, et al (1985): Persisting illness and fatigue in adults with evidence of Epstein-Barr virus infection. Ann Intern Med 102:7-16.

Sutton RE, Koob GF, LeMoal M, Rivier J, Vale W (1982): Corticotropin-releasing factor produces behavioural activation in rats. Nature 297:331-333.

Swartz MN (1988): The chronic fatigue syndrome—one entity or many? N Fng J Med 319:17261728.

Swerdlow NR, Geyer MA, Vaie WW, Koob GF (1986): Corticotropin-releasing factor potentiates acoustic startle in rats: Blockade by chlordiazepoxide. Psychopharmacology (Berlin) 88:147152.

Taerk GS, Toner BB, Salit IE, Garfinkel PE, Ozersky S (1987): Depression in patients with neuromyasthenia (benign myalgic encephalon!yelitis). Int J Psychiatry Med 17:49-56.

Tobi M, Ravid Z, Feldman-Weiss V, et al (1982): Prolonged atypical illness associated with serological evidence of persistent Epstein-Barr virus infection. Lancet i:61-64.

Tomori N, Suda S, Tozawa F, Demura H, Shizume K, Mouri T (1983): Immunoreactive corticotropin-releasing factor concentrations in cerebrospinal fluid from patients with hypothalamicpituitary-adrenal disorders. J Clin Endocrinol Metab 56(6):1305-1307.

Wessely S, Powell R (1989): Fatigue s jndromes: A comparison of chroric "postviral" fatigue with neuromuscular and affective disorders. J Neurol Neurosurg Psychiatry 52:940-948.

Wood P (1941): Aetiology of Da Costa's syndrome. Br Med J June 7 p. 849. 